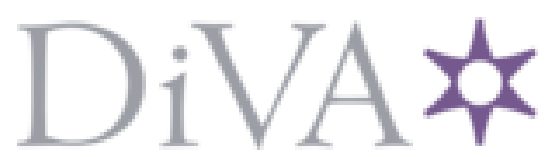

http://www.diva-portal.org

\title{
Postprint
}

This is the accepted version of a paper published in Journal of Risk Research. This paper has been peerreviewed but does not include the final publisher proof-corrections or journal pagination.

Citation for the original published paper (version of record):

Olofsson, A., Öhman, S. (2015)

Vulnerability, values and heterogeneity: One step further to understand risk perception and behaviour.

Journal of Risk Research, 18(1): 2-20

http://dx.doi.org/10.1080/13669877.2013.879485

Access to the published version may require subscription.

N.B. When citing this work, cite the original published paper.

Permanent link to this version:

http://urn.kb.se/resolve?urn=urn:nbn:se:miun:diva-22736 


\title{
Journal of Risk Research
}

\section{Vulnerability, values and heterogeneity: one step further to understand risk perception and behaviour}

Anna Olofsson ${ }^{a} \&$ Susanna Öhman ${ }^{a}$

${ }^{a}$ Risk and Crisis Research Center, Mid Sweden University, Östersund, Sweden

To cite this article: Anna Olofsson \& Susanna Öhman (2015) Vulnerability, values and heterogeneity: one step further to understand risk perception and behaviour, Journal of Risk Research, 18:1, 2-20, DOI: 10.1080/13669877.2013.879485

To link to this article: http://dx.doi.org/10.1080/13669877.2013.879485

\begin{abstract}
The aim is to investigate differences in risk perception and behaviour among different population groups selected by gender, age, country of birth, disability, and sexual orientation in the light of general values and vulnerability. The analyses use data from two Swedish national surveys from 2005 and 2008. People with foreign background perceive controlled and dread risks as a greater threat than do native-born people, but there is no difference in behaviour when general values and vulnerability have been controlled for. Compared to women, men rate known and dread risks as lower, but controlled risks as higher. Further, men's behaviour is more risk oriented and less risk-reducing, and homosexuals and bisexuals are more likely than heterosexuals to report risk behaviour. Compared to previous studies of the so called White Male Effect done in the United States, gender does not play a similar role in Sweden. On the contrary, it seems as if gender is of less importance and that the strength of the association varies depending on type of risk or risk behavior.
\end{abstract}

\section{INTRODUCTION}

The populations of European societies are becoming increasingly diverse, in part the result of the twin processes of globalisation and individualisation. To take one example, in 2006 some 1.3 million people or 14 percent of the Swedish population had another country of birth, and 20 per cent of the population had at least one parent who had been born abroad (Marklund, 2007). This variety of experience, combined with phenomena such as global travel for pleasure, the mass media, the Internet and with the increased responsibility of the individual, challenges not only traditional sociological theories, but also the detail in which they are examined and the standard reasons offered by way of explanation (cf. Beck, 2003; Therborn, 2000). Society has become more heterogeneous. 
However, global risk - be it war, climate change, threats to national security, or the ordinary hazards of daily life - is not 'evenly' distributed across nations and populations, and instead is determined by both socio-economic and geographical position. In other words, there are many social groups in Western countries who do not feel their life and circumstances to be secure, or sense that they are not respected by their fellow citizens or by society at large, and thus can be considered vulnerable. Conspicuous amongst them are immigrants, the disabled, the elderly, and homosexuals and bisexuals.

Thus far few studies have systematically examined the way the forces of heterogeneity influence risk perception and behaviour. Earlier studies have either focused exclusively on ethnicity and gender (e.g. Flynn, et al., 1994; Olofsson and Rashid, 2011; Palmer, et al., 2001) or on specific risk factors such as labour market participation, risk-related health behaviour, or environmental concern (e.g. Abbott, et al., 2006; Adeola, 2004; Cebulla, 2004; Silmak and Dietz, 2006). Like risk perception studies in general, these studies seldom explain the differences in risk perception between groups (cf. Sjöberg, 2000a). With a few exceptions (e.g. Cebulla, 2007, 2009; Kahan, et al., 2007; Tulloch and Lupton, 2003) the results are left unexplained (Gustafson, 1998). Researchers have tried to develop causal models of the relationship between socio-structural factors, personal values, and risk perceptions, using the former to explain the latter (e.g. Silmak and Dietz, 2006; Stern, et al., 1995), yet this approach has almost exclusively been limited to environmental concerns, while the question of other risks and population heterogeneity has been ignored. It is also the case that such studies tend to be descriptive rather than analytical. Another example of a factor rarely used in understanding differences in risk perception is the role of vulnerability in terms of social and economic resources and the experience of risk. Recently, theoretical developments problematizing the way gender differences in risk perception are investigated, questioning the instrumental way it has been used so far, point to that the effects made by gender should recognize gender's social influence and its cultural context (Henwood, Parkhill and Pidgeon, 2008).

Inspired by this approach, in this paper we consider risk perception and risk behaviour among different Swedish population groups selected by gender, age, country of birth, disability, and sexual orientation. However, it is not membership of these different groups per se that explains why these individuals might have different perceptions of risk. On the contrary, it can be assumed that behind structural factors such as gender, ethnicity, disability, and sexuality we can glimpse latent factors such as a sense of vulnerability, risk exposure, lack of power, subculture allegiance, and exclusion. Furthermore, individual values that are based on cultural norms can also be mediated through such heterogeneity factors, and consequently serve to explain differences in risk perception and behaviour. It is for this reason that individuals' general values and vulnerability will be used here as independent variables in the analysis.

The aim of this study is to investigate possible differences between population groups in risk perception and risk behaviour in the light of general values and vulnerability. Moreover, different categories of risk and risk behaviour will be studied in order to detect any variations in the influence of heterogeneity, values, and vulnerability on different kinds of risk perceptions and risk behaviour. By introducing heterogeneity, general values, and vulnerability to the study of risk perception and risk behaviour we can add a sociological 
approach to risk to the more psychological, individual-realist approach and add new knowledge to risk research (cf. Taylor-Gooby and Zinn, 2006).

\section{THEORY AND PREVIOUS RESEARCH}

Studies of risk perception and self-professed risk behaviour ${ }^{\mathrm{i}}$ have repeatedly shown that personal risks are generally perceived to be less dangerous than risks to society or the general public (Frewer, et al., 1994; Sjöberg, 2000a); that the layman's evaluation of risk differs from the expert's (e.g. Bier, 1999; Slovic, et al., 1991); and that risk perception differs between people of different ages, education, place of residence, and political orientation (Dekker, et al., 1997; Dietz, et al., 1998; Dunlap and Jones, 2002; Rhodes \& Pirik, 2011). It has also been shown that people of different ethnicities, and men and women, vary in risk perception (Finucane, Slovic, et al., 2000; Flynn, et al., 1994). Women and minorities are more concerned by risk than white males, the so-called 'White Male Effect' (Cabrera and Leckie, 2009; Enander and Johansson, 2002; Finucane, et al., 2000; Flynn, et al., 1994; Johnson, 2004; McCright and Riley, 2013; Renn, 2000; Satterfield, et al., 2004; Weber and Hsee, 1998). This means that native men's risk perception differs from other groups in a society (McCright and Riley, 2013), although there are research indicating that race, or ethnicity, is a more important factor in understanding risk perception (Johnson, 2004; Olofsson \& Rashid, 2011).

However, few studies have offered a sufficient explanation of the White Male Effect or of differences between different socio-cultural groups, other than by offering rudimentary statistical analyses that point to lower levels of control and influence over both individual and societal issues among these groups, and differences in basic values or 'risk cultures' (Finucane, Slovic, et al., 2000; Gutteling and Wiegman, 1996; Mohai and Bryant, 1998; Palmer, 2003; Tulloch and Lupton, 2003). In general, the focus on gender and race differences are many times shallow and seldom theoretically informed (Gustafson, 1998). Risk, as most things in life, is gendered and raced which will have an impact both on how people perceive it and act towards the risk (cf. Henwood, Parkhill and Pidgeon, 2008). Similarly, other groups, such as homosexuals, bisexuals, and the disabled, have been more or less ignored by the risk research community, although there are reasons to believe that similar structural differences exist amongst these groups (Monteiro et. al., 2010; Quilgars, et al., 2008).

We have broadened the scope of our investigation to include these groups, using two theoretical concepts - values and vulnerability - to show how gender, ethnicity, disability and sexuality are socially and culturally embedded. Values, a rather vague concept that dates back to the early years of sociology, is a term used in fields as diverse as social structural processes and social psychological phenomenon (Durkheim, 1993[1893]; Hiltin and Piliavin, 2004; Parsons and Shils, 1951). In empirical terms, studies such as those of ethnic groups with stable intra-group homogeneous and inter-group heterogeneous values are common (Kuhnen and Oysterman, 2002), but sociological work on values has been relatively sparse since the mid 1960s (Hiltin and Piliavin, 2004). Instead, psychologists and social psychologists dominate the field (e.g. Rokeach, 1973; Schwartz, 1994), and research on values has often focused on the individual or personality based aspects of values (Hiltin and Piliavin, 2004), or, in order to prove either the existence of universal values (e.g. Schwartz, 1994) or universal 
value changes (e.g. Inglehart, 1977; Inglehart and Baker, 2000), on cross-national aspects. Thus research on values tends to focus on the homogeneity of values rather than their dissimilarities in different groups, regions or countries.

To identify and explain group differences, neither a purely structural nor an individual concept of values is sufficient. We have therefore turned to cultural theory (Dake, 1992; Douglas and Wildavsky, 1982). Originally, Douglas and Wildavsky (1982) criticised the focus on individual explanations of values, and argued that basic values that permeate certain contexts serve to shape the individual's perception of risk, described in the 'grid-group' typology (Douglas, 1970). Grid represents 'social control', or the pervasiveness and significance of social differentiation norms, and the group represents 'social commitment', or the extent to which an individual is absorbed and sustained by group membership. Four typical cultural categories - egalitarianism, hierarchy, fatalism, and individualism - have been developed from the typology, each in which risk is understood differently. Viewed on an individual level, these categories can influence people's perceptions. People with a hierarchical world-view, or who are embedded in a hierarchical context, accept risk as long as the authorities or experts can justify it, while they fear risks that threaten the social order. Egalitarians reject risks that presage irreversible danger to the general public or to future generations, and those that are forced on them by the decisions of experts or authorities. Individualists fear risks that curb their freedom, but they can also perceive risk as an opportunity. Fatalists, meanwhile, try not worry about things that they believe they cannot influence. At the beginning of the 1990s, Dake (1991) introduced the first quantitative measurements, an approach since broadly applied in quantitative studies of cultural theory and risk (Dake, 1991; 1992; Marris, et al., 1998; Peters and Slovic, 1996). Sjöberg (1996, 1998, $1999,2000 \mathrm{a}, \mathrm{b})$ shows that the relation between cultural biases and perception of risk is robust but weak in Sweden (about $5 \%$ of explained variance), and that studies carried out in Europe in general seem to find weaker relations between cultural bias and risk perception compared to studies from the U.S. (Sjöberg 2000b). This indicates that there might be differences in the role played by values more generally and cultural basis specifically in different geographical contexts. However, some patterns seem to be rather stable, e.g. women tend to report egalitarian biases to a higher degree than men, while men agree more with individualistic and hierarchical values (Flynn et al., 1994; Grenstad, 2000). Sjöberg argues that cultural theory fails because it tries to capture the social context, which is too abstract and farfetched, and because the social context is not the only determinant of risk perception (Sjöberg, 2000b). We agree in so far that the relationship between factors in the social context and the perception of the individual is difficult to measure and this is probably the reason why explained variance is quite low. However, explained variance is not the sole factor to define whether a variable is relevant or not (Finucane and Holup, 2005; Marris et al., 1998). On the contrary, it is important to try to identify such factors and find better ways of measuring them. In this study we therefore use another operationalisation of cultural theory (Rippl, 2002) than Sjöberg used.

To explain the White Male Effect it is common to refer to cultural theory or values. Even in the original study of 1994, Flynn et al. showed that white males have less egalitarian and more hierarchical values than other groups. Since then there have been a number of studies that use a variety of value measurements (e.g. Kahan, et al., 2007; Kalof, et al., 2002, cp. Johnson, 2004). Rippl (2002) has further developed the method of measurement and tested the 
poor level of validity. We have chosen to apply cultural theory by using Rippl's (2002) operationalisation, which is an improved scale based on Dake's (1991) first operationalisation of Douglas and Wildavsky's (1982) original theory. Unique to this present study is the inclusion of risk behaviour and of the additional heterogeneity factors such as sexual orientation and disability.

Vulnerability is not much used as an explanatory factor in studies of risk perception. On the contrary, it is normally equated with research on social inequality, health and even disasters, but not with risk research. However, our argument is that vulnerable people probably have a greater aversion to risk as well, and to that end we draw on the literature on social vulnerability (Wisner, et al., 2004). In disaster research, social vulnerability is defined as '...the characteristics of a person or group and their situation that influence their capacity to anticipate, cope with, resist or recover from the impact of a hazard.' (Wisner et al., 2004: 11). Empirical studies support this, showing that after a disaster, immigrants, single mothers, children, the poor, and ethnic minorities are more affected and receive less help than other groups (Bolin, 1986; Morrow, 1999; Peacock, et al., 1997). Thus groups that have limited economic resources, belong to lower social strata, and live in deprived areas are less resilient to crises and disasters (Barnshaw and Trainor, 2007).

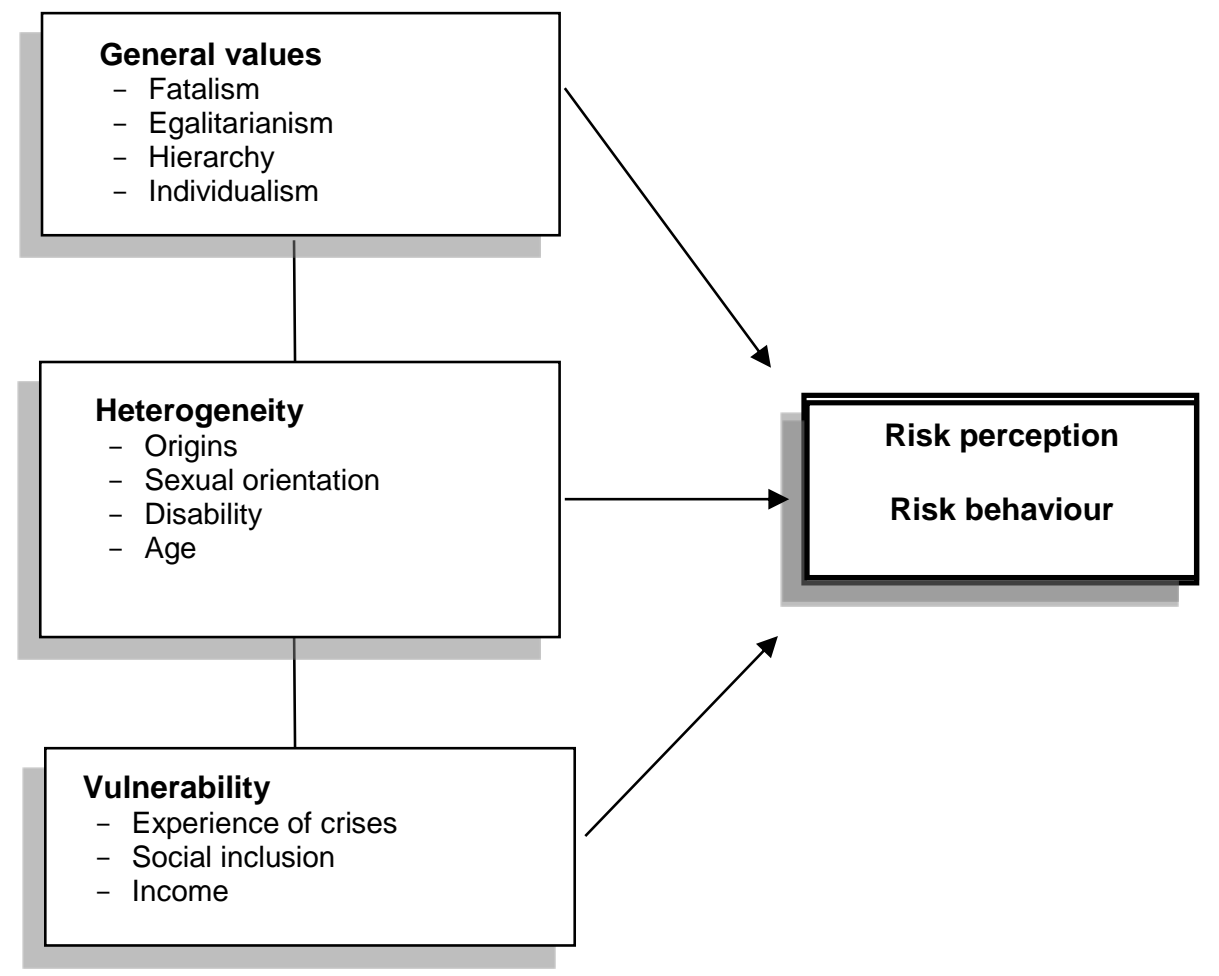

Figure 1. The relationships between independent variables, risk perception, and risk behaviour.

Risk perception studies, and particularly studies of the White Male Effect, touch on the concept of vulnerability to the extent of including income and education in their reckoning, as well as measurements of perceived personal control and influence over public issues, and the experience of discrimination and/or economic and physical disadvantages (Finucane et al., 2000; Flynn et al., 1994; Satterfield, Mertz and Slovic, 2004). The results show that women 
and ethnic minorities have a lower level of education and income than comparable white men and that vulnerable men perceive risks in a similar manner as women. As expected, there seems to be a relationship between vulnerability and heterogeneity factors such as gender and ethnicity, and it is not far-fetched to propose that there are similar relationships with disability and sexual orientation.

Hence we would argue that vulnerability is important both for risk perception and risk behaviour, and is mediated through heterogeneity factors such as age, gender, origin, disability, and sexual orientation. In the present study, three measurements of vulnerability have been used: experience of crises, social inclusion, and economic resources (cf. Dwyer, et al., 2004; Olofsson, 2007; Olofsson and Öhman, 2009).

Figure 1 outlines the relationships between the independent and dependent variables. The model stipulates both direct and indirect relationships of values and vulnerability with risk perception and risk behaviour, where indirect relationships are mediated by heterogeneity factors. Thus the model highlights the interdependency of heterogeneity factors, values, and vulnerability that that is related to individual risk perception as well as risk behaviour. However, the indirect relationship will not here be explicitly measured in the empirical models, although it is important to bear it in mind when interpreting the results.

\section{METHOD AND MATERIAL}

The analyses use data from two Swedish national surveys, 'Society and Values', that took the form of mail polls conducted in the winters of 2005 and 2008. Both polls used questionnaires that focus on risk perception, risk communication, risk behaviour, experience, and values. The resultant data sets used in the present analyses comprise two representative samples of the Swedish population between the ages of 16 and 75. The two samples in the 2005 survey were a national random sample $(n=2000$, response rate $59 \%)$ and a local random sample of people living in three municipal wards in Stockholm, Gothenburg and Malmö $(n=750$, response rate $39 \%$ ), all residential areas with a high proportion of inhabitants with foreign backgrounds. In 2008 there were two similar samples but a lower response rate (national random sample $\mathrm{n}=2000$, response rate $41 \%$; local random sample $\mathrm{n}=750$, response rate $25 \%$ ). The total number of respondents was 1,472 in 2005 and 951 in 2008. The marked decrease in response rate may have several explanations: fewer reminders were sent out in 2008 compared with 2005; in 2005 phone reminders were available for longer, making it possible to reach more potential respondents; and, generally speaking, it has been noted that Swedes are increasingly unwilling to participate in polls.

In both surveys the second, local sample was included to increase the number of respondents with foreign backgrounds. Due to language problems and issues with home addresses, the response rate was expected to be low. It would have been desirable to have subsamples of homosexuals, bisexuals, and the disabled, but it proved impossible. This means that the number of homosexual and bisexual respondents was low ( $2005 \mathrm{n}=48,24$ women and 24 men; $2008 \mathrm{n}=28,19$ women and $9 \mathrm{men}$ ), as was the number of disabled people (2005 $\mathrm{n}=132$, 66 women and 66 men; $2008 \mathrm{n}=60,32$ women and 28 men). One large group of people of foreign background were those with origins in neighbouring Nordic countries, and it is known from earlier research that they do not differ significantly in risk perception from 
native Swedes (e.g. Olofsson and Öhman, 2006) so these respondents were excluded. A small group of respondents originating from different Western European countries, Canada, and the US were also excluded for similar reasons. Remaining were 222 respondents in 2005 (114 women and 108 men) and 103 in 2008 (53 women and 49 men) with foreign backgrounds, predominately from the Middle East and the former Yugoslavia.

The surveys included a large number of items based on earlier studies (e.g. Sjöberg, 2000a) and a pre-study of five focus-group interviews (Olofsson and Öhman, 2007). The majority of the items used here were identical in both surveys; their empirical design echoes the outline in Figure 1.

\section{Independent variables}

Heterogeneity was measured according to country of origin, sexual orientation, disability, gender, and age. Since the first three variables have already been described, and gender was a simple binary choice, age remains to be described in greater detail. Previous research indicates that age does not have a linear relationship with perception of risk or risk behaviour (see Slovic, 2000), so the respondents were divided into three roughly equal groups: 'young $16-35$ years old (33\%t in 2005, $29 \%$ in 2008); 'middle aged' 36-52 years old (30\% in 2005, $31 \%$ in 2008); and 'old' 52-75 years old (36\% in 2005, $39 \%$ in 2008).

In order to measure general values, Rippl's (2002) revised cultural bias scale (based on Dake, 1991) was translated and applied. The scale has 18 items with outcomes expected to fall into one of four categories: fatalism, egalitarian, hierarchy, and individualism. This was confirmed using a factor analysis (principal component analysis, Varimax rotation) and four new variables were created using the factor scores. The same procedure was followed for each data set, with similar results.

Similarly, to measure vulnerability, factor analyses were used to create 'social inclusion' indexes. There are five items in each survey to gauge whether the respondents feel they are accepted as they are in the Swedish society which together amount to a one-dimensional factor ranging from exclusion to inclusion. The second measurement of vulnerability, 'experience of crises', was also constructed as an index. Respondents were asked if they had experienced any or several of six different risks (including fire, serious illness, natural catastrophe, and traffic accident). ${ }^{\text {ii }}$ The answers were merged into an index with a 0-6 range. The final vulnerability factor, 'economic resources', was measured using stated income, and was subsequently converted into three levels - low, middle, and high - that correspond roughly to monthly economic incomes of $€ 0-€ 1,359, € 1360-€ 2,270$, and more than $€ 2,270$ respectively. ${ }^{\text {iii }}$

\section{Dependent variables}

This paper considers risk perceptions and risk behaviour. Risk perceptions were measured in the polls using sixteen separate items, each consisting of a statement designed to elicit the degree to which respondents viewed the risk in question as a personal threat (based on Sjöberg, 1998; Slovic, et al., 1977). This risk scale is supposed to resolve into four categories of risk: known risks, unknown risks, controlled risks, and so-called dread risks. Using factor analyses, our data formed three categories, namely known risks (traffic accidents, accidents in relation to recreational activities, serious illnesses, and stress), controlled risks (smoking, 
drinking alcohol, and HIV), and dread risks (GMO, climate change, natural catastrophes, terrorism etc), with the difference from earlier studies (e.g. Slovic, et al., 1977) being that 'unknown risks' and 'dread risks' have merged. This can be explained by the fact that certain risks that some fifteen or twenty years ago were defined as unknown, such as nuclear power and gene technology, are today widely held to be known and are thus perceived as dread risks. The questions and factor solutions were the same for both surveys, confirming the stability of the results.

The second dependent variable was self-professed risk behaviour. Two kinds of questions were asked, the one to gauge risky behaviour and the other risk-reducing behaviour. Unfortunately the two surveys were not completely identical on this point. In 2005, risky behaviour was measured using two items about walking home alone late at night and having unprotected casual sex, while risk reduction behaviour was measured using three items on traffic safety (bicycle helmet use, high visibility accessories, and safety belts). In 2008 there were only two items on risk reduction behaviour (bicycle helmets and high visibility accessories) because almost all respondents in 2005 said they used a safety belt. Risk behaviour, on the other hand, included not only the two questions used in 2005 but also items to measure the extent to which respondents drank alcohol and smoked. The factor analysis of the items for each year was conducted separately, and although the results were similar. Two factors were found each year: risky behaviour and risk-reducing behaviour. However, when interpreting the results the specific differences concerning the two additional questions 2008 about alcohol and smoking should of course be borne in mind.

\section{Caveats}

The study has limitations. One of the main concerns is the low level of explained variance. Even though this is not unusual in survey research about social phenomenon and one could argue that it is also important to identify patterns and not only explain particular phenomenon (Finucane and Holut, 2005), the results should be interpreted with this in mind. Another concern is the low number of respondents with disabilities, foreign backgrounds, particularly women, and homo- and bisexuals. This may reduce the representativeness of the study, while also possibly reducing our chances of observing effects.

\section{RESULTS}

Regression models were use to analyse risk perception and risk behaviour. The models comprise the determinants; heterogeneity, general values, and vulnerability. Bivariate analysis of each heterogeneity factor and each dependent variable was used to establish the relationships between heterogeneity, risk perception, and risk behaviour. The results are summarised in Table 1.

Clearly there is reasonable consistency over time, given the similarity of the results from both surveys. Origin, gender, and age are the three independent variables that have an effect on most dependent variables: people with foreign backgrounds state higher perception of controlled and dread risks, greater risk behaviour, and lesser risk-reducing behaviour. In terms of gender, the general trend is for men to be less inclined to perceive risk as high than women, matched with a greater degree of risk-related behaviour and less risk reduction. That said, there is one inconsistency, for in 2008 the levels of controlled risk were greater for men than for women. Age is also clearly related both to perception of risk and risk behaviour. The 
oldest are less concerned with known risks compared with the young, but show greater risk reduction and are less likely to indulge in risk behaviour.

Table 1. Bivariate regressions of heterogeneity factors and dependent variables (risky perception and risk behaviour) with the direction of the correlation indicated $\left({ }^{\wedge} p=<.1, * p=<.05, * * p<.01.\right)$.

\begin{tabular}{|c|c|c|c|c|c|c|c|c|c|c|}
\hline & \multicolumn{2}{|c|}{$\begin{array}{l}\text { Known } \\
\text { risks }\end{array}$} & \multicolumn{2}{|c|}{$\begin{array}{c}\text { Controlled } \\
\text { risks }\end{array}$} & \multicolumn{2}{|c|}{$\begin{array}{l}\text { Dread } \\
\text { risks }\end{array}$} & \multicolumn{2}{|c|}{$\begin{array}{c}\text { Risky } \\
\text { behaviour }\end{array}$} & \multicolumn{2}{|c|}{$\begin{array}{c}\text { Risk reduction } \\
\text { behaviour }\end{array}$} \\
\hline & 2005 & 2008 & 2005 & 2008 & 2005 & 2008 & 2005 & 2008 & 2005 & 2008 \\
\hline Foreign background & -.034 & .044 & $.209^{\star \star}$ & $.256^{\star \star}$ & $.295^{\star \star}$ & ,277** & $.111^{\star *}$ & .006 & $-.107^{\star \star}$ & $-.057^{\wedge}$ \\
\hline Homo-/ bisexual & .006 & .008 & .045 & .053 & .018 & .049 & $.129^{\star *}$ & $.112^{\star \star}$ & .016 & -.017 \\
\hline Disabled & .000 & .049 & .000 & -.001 & .020 & .005 & -.004 & -.004 & .017 & .010 \\
\hline Male & $-.160^{\star \star}$ & .002 & $-.131^{\star \star}$ & $.119^{\star \star}$ & $-.062^{*}$ & $-.127^{\star \star}$ & $.284^{\star \star}$ & $.128^{\star \star}$ & $-.160^{* *}$ & $-.155^{\star \star}$ \\
\hline $\mathrm{Age}^{\mathrm{a}}$ & $-.193^{\star *}$ & $-.095^{* *}$ & .006 & -.025 & $.077^{* *}$ & .029 & $-.258^{\star *}$ & $-.165^{\star \star}$ & $.159^{* *}$ & $.105^{\star *}$ \\
\hline
\end{tabular}

${ }^{\mathrm{a}}$ Age has been used as a continuous variable

Two of the heterogeneity factors show little or no relationship to risk, namely sexual orientation and disability. However, both are statistically related to single risk items in partial regressions of single risk items (the original sixteen risks that were factor analysed plus the various items on risk behaviour). ${ }^{\text {iv }}$ Thus we retained these variables in the multivariate analyses, while noting that they would probably not have an impact on the outcome.

Table 2. Multiple regression models (hierarchical regression) of risk perceptions with independent variables(heterogeneity, general values, and vulnerability), with the direction of the correlation indicated $(\wedge p=<.1, * p=<.05, * * p<.01$.$) .$

\begin{tabular}{|c|c|c|c|c|c|c|}
\hline & \multicolumn{2}{|c|}{ Known risks } & \multicolumn{2}{|c|}{ Controlled risks } & \multicolumn{2}{|c|}{ Dread risks } \\
\hline & 2005 & 2008 & 2005 & 2008 & 2005 & 2008 \\
\hline \multicolumn{7}{|l|}{ Heterogeneity } \\
\hline Foreign background & -.036 & -.002 & $.145^{\star \star \star}$ & $.209^{* *}$ & $.266^{\star *}$ & $.229^{* *}$ \\
\hline Homo- or bisexual & .016 & -.012 & .044 & .044 & -.006 & .026 \\
\hline Disabled & -.007 & .029 & -.045 & -.013 & -.023 & -.022 \\
\hline Men & $-.054^{\wedge}$ & -.017 & .045 & $.104^{* *}$ & $-.113^{* \star}$ & $-.146^{\star *}$ \\
\hline Middle aged & .003 & -.059 & .052 & .013 & $.061^{\wedge}$ & $.087^{*}$ \\
\hline Old & -.056 & $-.107^{*}$ & $.122^{\star \star}$ & $.085^{\wedge}$ & $.136^{* *}$ & $.188^{* \star}$ \\
\hline \multicolumn{7}{|l|}{ General values } \\
\hline Fatalism & $-.051^{\wedge}$ & -.032 & $.099^{\star *}$ & $.108^{* *}$ & .043 & .049 \\
\hline Egalitarianism & $-.058^{\wedge}$ & -.007 & .036 & .036 & $.048^{\wedge}$ & $.118^{* \star}$ \\
\hline Hierarchy & .024 & $.083^{*}$ & $-.055^{\wedge}$ & $-.075^{\star}$ & $.057^{\wedge}$ & $.076^{\star}$ \\
\hline Individualism & .027 & -.012 & $.105^{\star \star}$ & $.069^{\wedge}$ & .006 & .034 \\
\hline \multicolumn{7}{|l|}{ Vulnerability } \\
\hline Experience & $.139^{\star *}$ & $.234^{\star \star}$ & $.067^{*}$ & .022 & $.082^{\star \star}$ & $.089^{* *}$ \\
\hline Inclusion & $-.057^{\wedge}$ & -.030 & .012 & .030 & $-.055^{\wedge}$ & $-.066^{\wedge}$ \\
\hline Income, middle & $.086^{\star *}$ & -.001 & -.023 & -.039 & -.026 & -.057 \\
\hline Income, high & $.067^{\wedge}$ & .025 & $-.102^{\star *}$ & $-.100^{\star}$ & -.016 & -.064 \\
\hline Adjusted $\mathrm{R}^{2}$ & .031 & .052 & .083 & .097 & .121 & .124 \\
\hline
\end{tabular}

In Table 2, multiple regression models are estimated for the three factors of risk perception known risks, controlled risks and dread risks - including all three of the independent 
variables, heterogeneity, general values, and vulnerability. Hierarchical regression was used in order to show the effect of the different sets of independent variables. ${ }^{\mathrm{v}}$

Generally, the effect of heterogeneity is weaker in the multivariate analyses than in the bivariate analysis. If we examine the results focusing on one risk at a time, beginning with known risks (for example, the respondent's personal risk of contracting cancer or experiencing a traffic accident), the effects of gender and age essentially disappear when general values and vulnerability are added to the model. Still, the pattern that the older are less likely than the young to view these risks as considerable persists in the 2008 survey. More interesting is vulnerability's role in known risks: all three variables are significant in the 2005 survey, and the pattern is more or less unchanged in 2008. People with greater experience of risk are more concerned by known risks, and the same is true of people who feel excluded from society. Furthermore, people with middle or high incomes perceive these risks to be greater than people with low incomes. General values also relate to known risks: fatalistic and egalitarian values both equate to lower risk perceptions. Overall, the power of the regression model is low, given that the adjusted $\mathrm{R}^{2}$ is only 0.031 (2005) and 0.052 (2008) for the full model. More interesting, by including vulnerability to heterogeneity and general values the model's fit increases from .009 to adjusted $\mathrm{R}^{2} .031$ in 2005 and from .0005 to .052 in 2008 (adjusted $\mathrm{R}^{2}$ ), indicating that vulnerability relatively speaking matters for risk perception of known risks.

If we turn to controlled risks, and specifically the personal risks associated with smoking and drinking, the pattern is slightly different. Of the heterogeneity factors, two contribute to the model: foreign background and age. People with a foreign background and the older perceive greater controlled risks than the native-born and the young. The effect of gender is no longer significant in 2005, but interestingly the 2008 results that men have higher risk perceptions persist from the bivariate analyses. General values seem to be an important factor, adding more to the fit of the model than the other heterogeneity factors. Three out of the four cultural biases show a significant correlation with the perception of controllable risks. People with fatalistic and individualistic values perceive these risks to be high, while people with more hierarchical values perceive them to be low. Experience of risk earlier in life is also related to a heightened risk perception, while high-income earners have a lower risk perception than low-income earners. The overall explanatory power is better than for known risks, but is still modest given that adjusted $\mathrm{R}^{2}$ is 0.083 (2005) and 0.097 (2008) for the full model.

Finally, turning to dread risks (the personal risks from climate change and terrorism, for example) we find that foreign background, gender, and age all contribute in the regression model. People with a foreign background, women, and the older tend to fear dread risks more than do native Swedes, men, and the young. Thus in this case there is no difference from the simple bivariate analyses, except that age remains significant in $2008 .{ }^{\text {vi }}$ Having strong egalitarian and hierarchical values is related to higher perceptions of dread risk. Lastly, vulnerability is shown to be significant: the more individuals feel excluded and the greater their experience of crises, the larger the perceived risk. Overall the explanatory power of the full regression model is 0.121 (2005) and 0.124 (2008) (adjusted $\mathrm{R}^{2}$ ). Adding values and general values have some effect for model fit, even though adjusted $\mathrm{R}^{2}$ for the model only including heterogeneity is .099 (2005) and .088 (2008). 
In Table 3, hierarchical multiple regression models are applied to risk and risk reduction behaviour. The results indicate that introducing general values and vulnerability does not affect much change, except that the importance of origin diminishes.

Table 3. Multiple regression models (hierarchical regression) of risky and risk-reducing behaviour with the independent variables (heterogeneity, general values and vulnerability), with the direction of the correlation indicated $\left({ }^{\wedge} p=<.1, * p=<.05, * * p<.01.\right)$.

\begin{tabular}{|c|c|c|c|c|}
\hline & \multicolumn{2}{|c|}{ Risky behaviour } & \multicolumn{2}{|c|}{ Risk reducing behaviour } \\
\hline & 2005 & 2008 & 2005 & 2008 \\
\hline \multicolumn{5}{|l|}{ Heterogeneity } \\
\hline $\begin{array}{l}\text { Foreign background } \\
\text { Homo- or bisexual }\end{array}$ & $\begin{array}{l}.034 \\
.085^{\star \star}\end{array}$ & $\begin{array}{l}-.062 \\
.091^{\star \star}\end{array}$ & $\begin{array}{l}-.038 \\
.039\end{array}$ & $\begin{array}{l}.000 \\
.003\end{array}$ \\
\hline Disabled & -.002 & -.016 & .015 & -.001 \\
\hline Male & $.270^{\star \star}$ & $.092^{\star \star}$ & $-.134^{\star *}$ & $-.144^{\star \star}$ \\
\hline Middle aged & $-.154^{\star *}$ & $-.127^{\star *}$ & $.121^{\star *}$ & .049 \\
\hline Old & $-.226^{\star *}$ & $-.114^{\star *}$ & $.152^{* *}$ & $.116^{\star \star}$ \\
\hline \multicolumn{5}{|l|}{ General values } \\
\hline Fatalism & -.015 & -.003 & $-.105^{\star *}$ & $-.105^{\star *}$ \\
\hline Egalitarianism & -.002 & -.011 & .032 & -.004 \\
\hline Hierarchy & $-.089^{\star *}$ & $-.158^{* *}$ & $.057^{\wedge}$ & .054 \\
\hline Individualism & $.076^{\star \star}$ & $.085^{\star}$ & $-.085^{\star *}$ & -.039 \\
\hline \multicolumn{5}{|l|}{ Vulnerability } \\
\hline Experience & $.079^{* *}$ & $.191^{* *}$ & .004 & $.064^{\wedge}$ \\
\hline Inclusion & -.048 & -.015 & .048 & $.066^{\wedge}$ \\
\hline Income, middle & -.024 & $.116^{\star *}$ & -.013 & .012 \\
\hline Income, high & -.029 & $.107^{*}$ & .010 & -.006 \\
\hline Adjusted $\mathbf{R}^{2}$ & .178 & .112 & .076 & .046 \\
\hline
\end{tabular}

If we begin with risky behaviour (for example, walking home alone late at night or having unprotected casual sex) we find that homosexuals or bisexuals report greater risky behaviour than heterosexuals. The same pattern is found amongst men and young people. Gender influences risky behaviour, in the sense that women report taking fewer risks than men. As already noted, the effect of origin is no longer significant. Furthermore, people with individualistic values are more likely to engage in risky behaviour, while people with strong hierarchical values are less inclined. Somewhat unexpectedly, increased exposure to risk relates positively to risky behaviour, so that individuals with a greater experience of crises take more risks compared with those who have had less experience. The results from 2008 also show that people with higher incomes engage in riskier behaviour. Overall the explanatory power of the regression models is 0.178 (2005) and 0.112 (2008) (adjusted $\mathrm{R}^{2}$ ) for the full model.

Turning to risk-reducing behaviour (for example, using a bicycle helmet or driving carefully), we find that women are more concerned than men, and the older are more concerned than the young. The effect of origin, on the other hand, is no longer significant. If we look at general values we find that people with strongly fatalistic values are less liable to reduce their risk behaviour, and the same is true of the respondents from 2005 with individualistic values. Vulnerability does not play as important a role as in the earlier analyses, but the results of the 2008 survey show that people who have experienced risk or 
who feel socially included report behaviour that tends more towards risk reduction. Overall the explanatory power of the full regression model is 0.076 (2005) and 0.046 (2008) (adjusted $\mathrm{R}^{2}$ ).

\section{CONCLUSIONS}

Most of the heterogeneity factors, namely origin, sexual orientation, gender, and age, clearly do have a role to play in how we should understand risk perception and risk behaviour, that is different groups do indeed perceive and act differently according to the kind of risk in question. These findings support the assumption that the heterogeneity of a society is one important clue in understanding risk perception and risk behaviour.

The results are presented in Figures 2 and 3 (cf. Figure 1), showing the three categories of independent variables - heterogeneity, general values, and vulnerability - and their relationship with the five dependent variables: perceptions of known, controlled, and dread risk, plus risky behaviour and risk reduction behaviour. Figure 2 summarises the results on risk perception, Figure 3 risk behaviour. The figures not only indicate the relationships but also give an indication of the variation in strength between the three categories of independent variables.

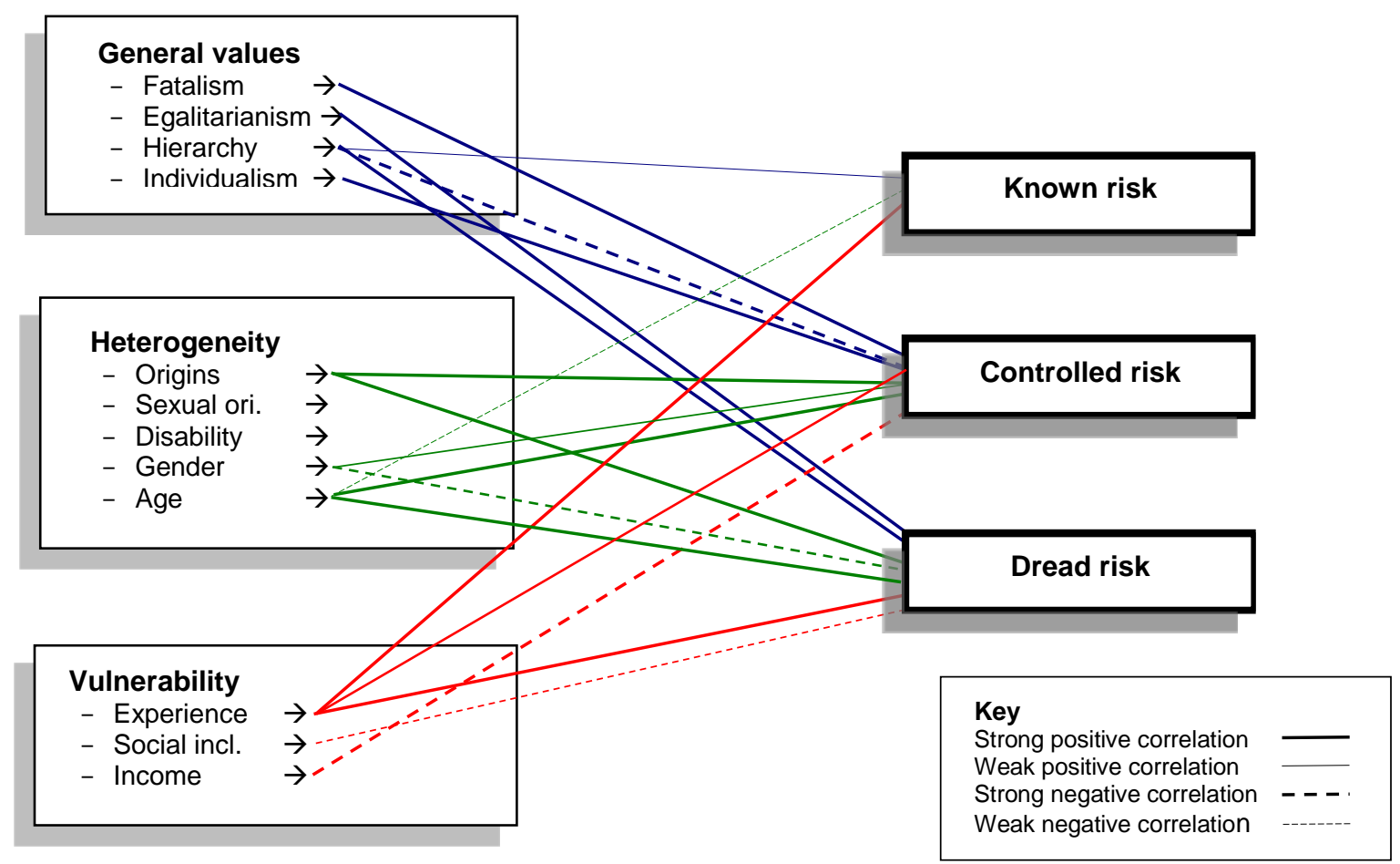

Figure 2. The empirical correlations between independent variables and risk perception.

As we have seen, people with a foreign background perceive controlled and dread risks as being a greater threat than do native-born people, but there is no difference in behaviour once general values and vulnerability have been taken into account. Compared with women, men rate known and dread risks as lower, but controlled risks as higher. Further, men's behaviour 
is more risky and shows less evidence of risk-reducing behaviour. Homosexuals and bisexuals are more likely than heterosexuals to report risky behaviour, but there the differences end. Finally, there is an age effect: unlike the young, the older are more fearful of dread risks, and are less likely to indulge in risky behaviour and the more so to reduce risk, while the young perceive known risks as being the greater. All these effects persist after general values and vulnerability are taken into account. However, disability does not seem prompt any notable differences, something that might reflect the small number of respondents.

The results for general values and vulnerability are similarly revealing. Having strong fatalistic and individualistic values makes people perceive controlled risks to be greater. At the same time, fatalists are less inclined to reduce their risk behaviour and individualists are more likely to increase it. People with hierarchical values take fewer risks, and their perception of dread risk is high, as is the case with egalitarians. In terms of vulnerability, the results show that people who have more experience of crises perceive known risks to be greater, but at the same time are more liable to risky behaviour. People who feel included in society perceive dread risks as lower than others, while income is related to all three kinds of perceived risks, but is only weakly related to risk behaviour.

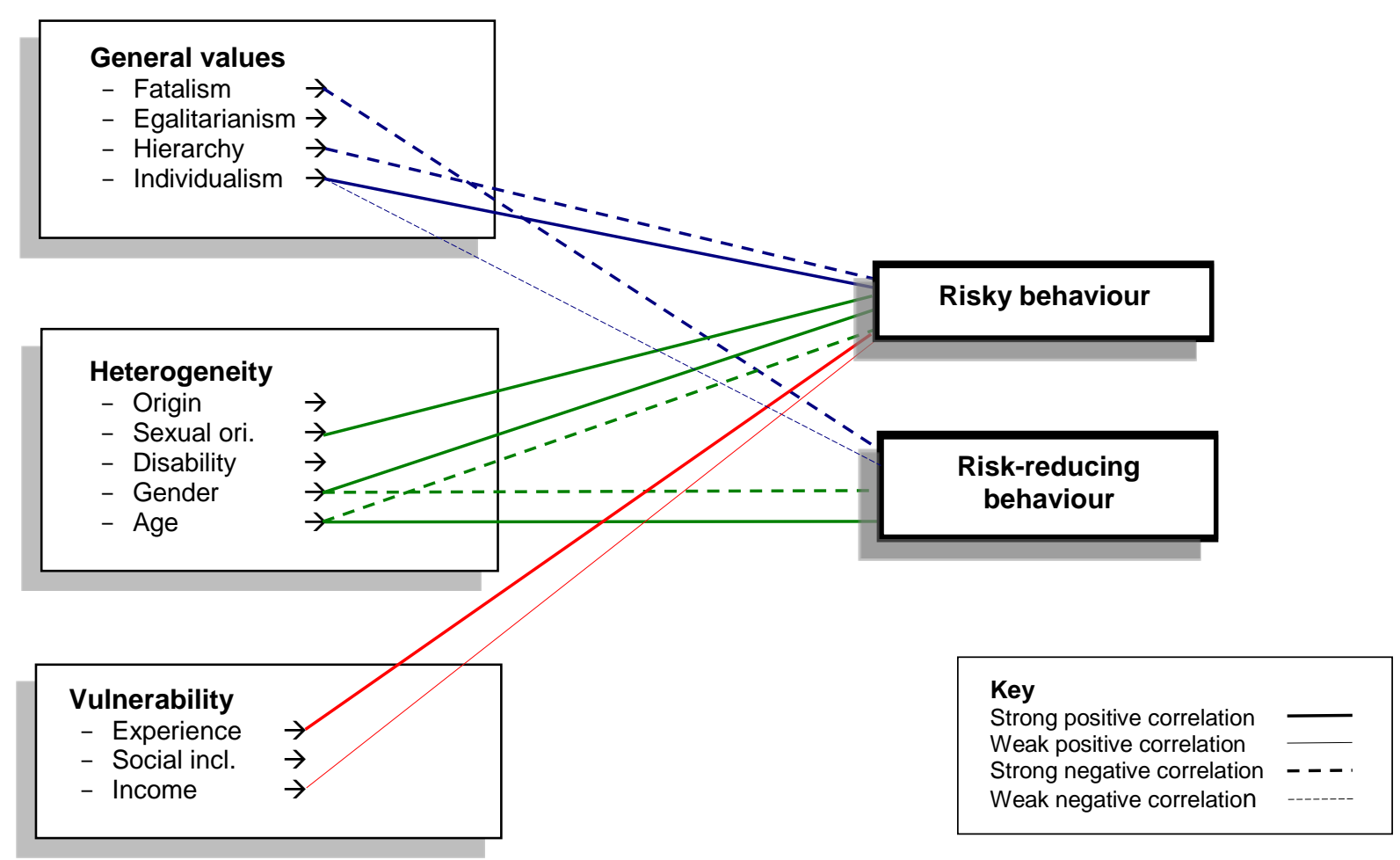

Figure 3. The empirical correlations between independent variables and risk behaviour.

The conclusion to be drawn from Figure 2 is that heterogeneity factors are related to perceptions of controlled and dread risk, but have only a weak link to known risks. Vulnerability, on the other hand, seems to be important for people's perception of known risks, and is also related to perceptions of dread risk, but shows only a weak connection with controlled risks. Lastly, general values show a pattern comparable with heterogeneity, in that 
there are strong correlations with the perception of controlled and dread risks, but only weak correlations with the perception of known risks. In other words, heterogeneity and values are associated with perceptions of controlled risks and dread risks, while vulnerability is related to perceptions of known risks.

Similarly, there are differences in self-professed behaviour. Interestingly, heterogeneity is related both to risky behaviour and risk reduction, even if the relationship is stronger with the former. The same is true for general values. There is a fairly strong relationship between values and risky behaviour, and a weaker one with risk-reducing behaviour. Once again, vulnerability differs from the other two categories of independent variables in being only related to risky behaviour. Thus the pattern displayed here is that heterogeneity and general values show similar patterns, while vulnerability is associated with risk perception and risky behaviour, but not risk reducing behaviour.

The use of general values and vulnerability to better understand risk perception and risk behaviour increases the explanatory power of the analyses. It is encouraging that, unlike much previous research, the present study shows the relatively stable and consistent influence of values (Kahan, et al., 2007; Palmer, et al., 2001; Palmer, 2003). Fatalistic, egalitarian, hierarchical, and individualistic values all influence risk perception and risk behaviour, and add to our understanding of these risk factors, although their power is relatively weak. Similarly, vulnerability also plays a role. It is particularly telling that while the greater the experience of risk, the greater the perceived risk, it is also strongly associated with risk behaviour. It is noteworthy that people with comparably higher risk perceptions, despite aware of the risks, are in fact more exposed to risk than others without actively seeking it out, perhaps because of their living conditions. Thus people with experience of crises ought to be studied further to trace the relationship between experience, perception, and behaviour, and the relationship, if any, to heterogeneity.

This shows the importance of introducing previous experience and social inclusion as measures of vulnerability into the analyses of risk perceptions and risk behaviour, not least because heterogeneity and vulnerability add to our understanding of risk by partly shifting the focus from individual characteristics to social differentiation, with all that means for risk perception and behaviour. Moreover, vulnerability is related to the perception of known risks in a way that neither heterogeneity nor general values are, leaving vulnerability an important complement to any understanding of risk perception.

One of the main arguments of this study is that heterogeneity factors do not in themselves explain differences in perception and behaviour, but are closely interrelated with other powerful social and contextual factors Our results show that introducing two sets of these factors to the mix moderates the strength of some of the heterogeneity factors, but not all. For example, by including vulnerability in terms of experience in the analysis of perceptions of known risks, the impact of gender disappears. Similarly, in the analysis of risk-reducing behaviour foreign background is not significant after the inclusion of values, specifically fatalistic values. With other words, adding values and vulnerability reduces the association between heterogeneity and risk perception as well as risk behaviour. In addition, it is conceivable that the different heterogeneity factors are influenced by different underlying causes, thus calling for a more complex model to detect the patterns of interdependence between values and country of origin, for example. Further developments of this model, based 
on a sociological approach to risk ought to include more contextual and socio-economic factors such as institutional trust, and social and economical resources, and identify the relations between these factors, the heterogeneity factors and risk perception and risk behaviour, by using a structural equation model for example.

The results also show, however, that the inclusion of general values and vulnerability increases the model's fit and explanatory power, but the effect of origins, sexual orientation, gender, and age still remains for many of the risks and behaviours investigated. Evidently work is called for to identify the underlying causes that influence the views and behaviour of these groups. Furthermore, it would be interesting to do comparative studies on an aggregated level to investigate how differences in the composition of heterogeneity may affect risk perceptions and behaviours in society.

In the case of Sweden, people with a foreign background, homosexuals and bisexuals do in some aspects of risk perception and risk behaviour differ from their comparable groups. Contrary to previous studies of the so-called White Male Effect gender does not play as significant role in Sweden, and even more interesting, with respect to certain types of risk men perceive the risk as higher than women (Olofsson and Rashid, 2011). This has important ramifications for the communication of risk and policy implementation. If nothing else, a better understanding of the relationship of heterogeneity, values, and vulnerability with perceptions of different kinds of risk and risk behaviour indicates the sheer complexity of risk as a social phenomenon. 


\section{REFERENCES}

Abbott, D., Quilgars, D. \& Jones, A. (2006). The impact of social and cultural difference in relation to job loss and financial planning: Reflections on the risk society. . Qualitative Social Research, 7(1), \#16. Retrieved from

Adeola, F. O. (2004). Environmentalism and risk perception: Empirical analysis of black and white differences and convergence. Society and Natural Resources, 17: 911-939.

Barnshaw, J. \& Trainor, J. (Eds.). (2007). Race class and capital amidst the hurricane katrina diaspora. Boulder: Rowman \& Littlefield.

Beck, U. (2003). Toward a new critical theory with a cosmopolitan intent. Constellations, 10(4): 453-468.

Bier, V. M. (1999). On the state of art: Risk communication to the public. Reliability Engineering and System Safety, 71: 139-150.

Bolin, R. (1986). Disaster impact and recovery: A comparision of black and white victims. International Journal of Mass Emergencies and Disasters, 4(1): 35.

Cabrera, N. L. \& Leckie, J. O. (2009). Pesticide risk: Communication, risk perception, and self-protective behaviors among farm workers in california's salina valley. Hispanic Journal of Behavioural Science, 31: 258-278.

Cebulla, A. (2004). Risk event and learning from error: When are assessments of the risk of unemployment revised? Risk Decision and Policy, 9: 297-315.

Cebulla, A. (2007). Class or individual? A test of the nature of risk perceptions and the individualizations thesis of risk society theory. Journal of Risk Research, 10(2): 129148.

Cebulla, A. (2009). Risk through the years - a statistical portrait of young people's risk perceptions and experiences relative to those of older generations. Journal of Youth Studies, 12(1): 39-56.

Dake, K. (1991). Orienting dispositions in the perception of risk. An analysis of contemporary worldviews and cultural biases. Journal of Cross-Cultural Psychology, 22: 61-82.

Dake, K. (1992). Myths of nature: Culture and the social construction of risk. Journal of Social Issues, 48(4): 21-37.

Dekker, P., Ester, P \& Nas, M. (1997). Religion, culture and environmental concern: An empirical cross-national analysis. Social Compass, 44(3): 443-458.

Dietz, T., Stern, P. C. \& Guangano, G. A. (1998). Social structural and social psychological bases of environmental concern. Environment and behaviour, 30(4): 450-471.

Douglas, M. (1970). Natural symbols: Explorations in cosmology. London: Barrie \& Rockliff.

Douglas, M. \& Wildavsky, A. (1982). How can we know the risks we face? Why risk selection is a social process. Risk Analysis, 2(2): 49-51.

Dunlap, R. E. \& Jones, R. E. (2002). Environmental concern: Conceptual and measurement issues. In R. E. Dunlap \& W. Michelson (Eds.), Handbook of environmental sociology. Westport: Greenwood Press.

Durkheim, E. (1993[1893]). The division of labour. Houndmills: Macmillan.

Dwyer, A., Zoppou, C., Nielsen, O., Day, S. \& Roberts, S. (2004). Quantifying social vulnerability: A methodology for identifying those at risk to natural hazards. Retrieved 21 July 2009, from Australian Government, Geoscience Australia www.ga.gov.au

Enander, A. \& Johansson, A. (2002). Säkerhet och risker i vardagen - en förutsättning för säkerhetsbeteende. Karlstad: Räddningsverket.

Finucane, M. L., Alhakami, A., Slovic, P. \& Johnson, S. M. (2000). The affect heuristic in judgments of risks and benefits. Journal of Behavioral Decision Making, 13(1): 1-17. 
Finucane , M. L., \& Holup, J. L. (2005). Psychological and cultural factors affecting the perceived risk of genetically modified food: and overview of the literature. Social Science \& Medicine, 60: 1603-1612.

Finucane, M. L., Slovic, P., Mertz, C. K., Flynn, J. \& Statterfield, T. A. (2000). Gender, race, and percieved risk: The 'white male' effect. Health, Risk \& Society, 2(2): 159-172.

Flynn, J., Slovic, P. \& Mertz, C. K. (1994). Gender, race, and perception of environmentalhealth risks. Risk Analysis, 14(6): 1101-1108.

Frewer, L., Shepard, R. \& Sparks, P. (1994). The interrelationship between perceived knowledge, control and risk associated with a range of food-related hazards targeted at the individual, other people and society. Journal of Food Safety, 14: 19-40.

Grenstad, G. (2000). Grid-group theory and plitical orientations: Effects of cultural biases in Norway in the 1990s. Scendinavian Political Studies, 23(3): 217-242.

Gustafson, P. (1998). Gerder differences in risk perception: Theoretical and methodological perspectives. Risk Analysis, 18(6): 805-811.

Gutteling, J. M. \& Wiegman, O. (1996). Exploring risk communication. Dordrecht: Kluwer Academic Publishers.

Henwood, K. L. Parkhill, K. A Pidgeon, N. F. (2008). Science, technology and risk perception; From gender differences to the effects made by gender. Equal Opportunities International, 27(8): 662-676.

Hiltin, S. \& Piliavin, J. A. (2004). Values: Reviving a dormant concept. Annual Review of Sociology, 30: 359-393.

Inglehart, R. (1977). The silent revolution: Changing values and political styles among western publics. Princeton: Princeton University Press.

Inglehart, R. \& Baker, W. E. (2000). Modernization, cultural change and the persistence of traditional values. Americal Sociological Review, 65(1): 19-51.

Johnson, B. B. (2004). Arguments for testing ethnic identity and cross-cultural as factors in risk judgments. Risk Analysis, 24(5): 1279-1287.

Kahan, D. M., Braman, D., Gastil, J., Slovic, P. \& Mertz, C. K. (2007). Culture and identityprotective cognition: Explaining the white male effect in risk perception. Journal of Empirical Legal Studies, 4(3): 465-505.

Kalof, L., Dietz, T., Guagnano, G. \& Stern, P. C. (2002). Race, gender and environmentalism: The atypical values and beliefs of white men. Race, Gender and Class, 9(2): 1-19.

Kuhnen, U. \& Oysterman, D. (2002). Thinking about the self influences thinking in general: Cognitive consequences of salient self-concept. Journal of Experimental Social Psychology, 38(5): 492-499.

Marklund, H. (2007). Finländarna fortfarande flest. Retrieved August 11, 2008, from www.scb.se

Marris, C., Langford, I. H. \& O'Riordan, T. (1998). A quantitative test of the cultural theory of risk perceptions: Comparison with the psychometric paradigm. Risk Analysis, 18(5): 635-647.

McCright, M. A \& Riley E. D. (2013). Bringing ideology in: the conservative white male effect on worry about environmental problems in the USA. Journal of Risk Research, (16)2 211-226.

Mohai \& Bryant. (1998). Is there a 'race' effect on concern to environmental quality? Public Opinion Quarterly, 62: 475-505.

Monteiro, S , Cecchetto, F, Vargas, E \& Mora, C. (2010). Sexual Diversity and Vulnerability to AIDS: the Role of Sexual Identity and Gender in the Perception of Risk by Young People. Sexuality Research and Social Policy, 7(4) 270-282.

Morrow, B. H. (1999). Identifying and mapping community vulnerability. Disasters, 23(1): 118. 
Olofsson, A. (2007). Crisis communication in multicultural societies: A study of municipalities in Sweden. International Journal of Mass Emergencies and Disasters, 25(2): 145-172.

Olofsson, A. \& Rashid, S. (2011). The white (male) effect and risk perceptions: Can equality make a difference? Risk Analysis. An International Journal, Spring 2011.

Olofsson, A. \& Öhman, S. (2006). General beliefs and environmental attitudes: Trans atlantic comparisions. Environment and behavior, 38(6): 768-790.

Olofsson, A. \& Öhman, S. (2007). Views of risk in Sweden: Global fatalism and local control. An empirical investigation of ulrich beck's theory of modern risks. Journal of Risk Research, 10(2): 177-196.

Olofsson, A. \& Öhman, S. (2009). Sårbarhet i det heterogena samhället. In A. Olofsson \& S. Öhman (Eds.), Risker i moderna samhällen: Samhällsvetenskapliga perspektiv. Lund: Studentlittertur.

Palmer, C., Carlstrom, L. K. \& Woodward, J. A. (2001). Risk perception and ethnicity. Risk Desision and Policy, 6 (3): 187-206.

Palmer, C. G. S. (2003). Risk perception: Another look at the 'white male' effect. Health, Risk \& Society, 5(1): 71-83.

Parsons, T. \& Shils, E. A. (1951). Toward a general theory of action. Cambridge, Mass.: Harvard Univ. Press.

Peacock, W. E., Morrow, B. H. \& Gladwin, H. (Eds.). (1997). Hurricane andrew: Ethnicity, gender, and the sociology of disaster. London: Routledge.

Peters, E. \& Slovic, P. (1996). The role of affect and worldviews as orienting dispositions in the perception and acceptance of nuclear power. Journal of Applied Social Psychology, 26(16): 1427-1453.

Quilgars, D., Jones, A. \& Abbott, D. (2008). Does difference make a difference in financial planning for risk? Social Policy \& Administration, 42(6): Quilgars, D., Jones, A. \& Abbott, D. (2008). Does Difference Make a Difference in Financial Planning for Risk? Social Policy \& Administration 2042 (2006), 2576-2592.

Renn, O. (2000). Cross-cultural risk perception: A survey of empirical studies. London: Kluwer Academic Publishers.

Rhodes, N \& Pivik, K. (2011). Age and gender differences in risky driving: the roles of positive affect and risk perception. Accident; analysis and prevention, 43(3) 923-31.

Rippl, S. (2002). Cultural theory and risk perception: A proposal for a better measurement. Journal of Risk Research, 5(2): 147-165.

Rokeach, M. (1973). The nature of human values. New York: Free Press.

Satterfield, T. A., Mertz, C. K. \& Slovic, P. (2004). Discrimination, vulnerability, and justice in the face of risk. Risk Analysis, 24(1): 115-129.

Schroder, K. E. E., Forsyth, A. D., Carey, M. P. \& Vanable, P. A. (2003). Methodological challenges in research on sexual risk behavior: Ii. Accuracy of self-reports. Annals of behavioral medicine. 26(2): 104-123.

Schwartz, S. H. (1994). Are there universal aspects in the structure and content of human values? Journal of Social Issues, 50: 19-45.

Silmak, M. W. \& Dietz, T. (2006). Personal values, beliefs and ecological risk perception. Risk Analysis, 26(6): 1689-1705.

Sjöberg, L. (1996). Discussion of the limitations of the psychometric and cultural theory aporaches to risk perception. Radiation Protection Dosimetry, 68(3/4): 219-225.

Sjöberg, L. (1998). Explaining risk perception: An empirical and quantitative evaluation of cultural theory. In R. Löfstedt \& L. Frewer (Eds.), Risk and modern society. London: Earthscan.

Sjöberg, L. (1999). Risk perceptionin Western Europe. Ambio, 28(6): 543-549. 
Sjöberg, L. (2000a). Precieved risk and tampering with nature. Journal of Risk Research, 3(4): 353-367.

Sjöberg, L. (2000b). Factors in risk perception. Risk Analysis, 20(1): 1-11.

Slovic, P. (2000). The perception of risk. London: Earthscan Publications.

Slovic, P., Fischhoff, B. \& Lichtenstein, S. (1977). Cognitive processes and social risk taking. In H. Jungermann \& G. de Zeeuw (Eds.), Decision making and change in human affairs. Dordrecht: Riedel.

Slovic, P., Flynn, J. H. \& Layman, M. (1991). Perceived risk, trust, and the politics of nuclear waste. Science, 254(5038): 1603-1607.

Stern, P. C., Dietz, T. \& Guangano, G. A. (1995). The new ecological paradigm in socialpsychological context. Environment and behaviour, 27(6): 723-743.

Taylor-Gooby, P. \& Zinn, J. O. (2006). Current directions in risk research: New developments in psychology and sociology. Risk Analysis, 26(2): 397-411.

Therborn, G. (2000). At the birth of second century sociology: Times of reflexivity, spaces of identity, and nodes of knowledge. Brittish Journal of Sociology, 51(1): 37-57.

Tulloch, J. \& Lupton, D. (2003). Risk and everyday life. London: Sage.

Weber, E. U. \& Hsee, C. (1998). Cross-cultural differences in risk perception, but crosscultural similarities in attitudes towards percieved risk. Management Science, 44(9): 1205-1217.

Wisner, B. P., Blaikie, B. P., Cannon, T. \& Davis, I. (2004). (Vol. 2nd). London: Routledge.

\footnotetext{
${ }^{\mathrm{i}}$ Self-professed risk behaviour has been largely overlooked, although the literature confirms that there are differences between the sexes and between ethnic groups; thus men, for example, tend to take fewer precautions than women (Cabrera and Leckie, 2009). It is, however, a common theme in health research, and particularly in relation to sexually transmitted diseases, where the methodological emphasis is on data gathered from individuals using material such as diaries (e.g. Schroder, et al., 2003).

${ }^{i i}$ In the 2008 survey an additional risk had been added, resulting in an index range of 0-7.

iii The income levels have been recalculated from Swedish kronor (SEK) to Euros using an exchange rate of SEK11 $=€ 1$.

${ }^{\text {iv }}$ Detailed information of these tests is available from the authors.

' In hierarchical multiple regression, the researcher determines the variables' order of entry, but it is otherwise similar to stepwise regression. This is an alternative to comparing betas to assess the importance of the independent variables. Each model consisted of three blocks, the first including all heterogeneity variables, the second the general values variables, and the third the vulnerability variables. In this way it is possible to see if adding another set of variables significantly adds to the overall model. The same structure was also used for the risk behaviour analyses.

${ }^{\mathrm{vi}}$ The difference might be explained by the fact that here age has been broken down into three age groups, whereas in the bivariate analysis it was used as a continuous variable.
} 